\title{
Fatigue behaviour and design of corroded reinforced concrete beams intervened by ICCP-SS
}

DOI:

10.1016/j.compstruct.2020.113295

\section{Document Version}

Accepted author manuscript

Link to publication record in Manchester Research Explorer

\section{Citation for published version (APA):}

Su, M., Wei, L., Liang, H., Zhu, J., Ueda, T., \& Xing, F. (2020). Fatigue behaviour and design of corroded reinforced concrete beams intervened by ICCP-SS. Composite Structures, 113295.

https://doi.org/10.1016/j.compstruct.2020.113295

\section{Published in:}

Composite Structures

\section{Citing this paper}

Please note that where the full-text provided on Manchester Research Explorer is the Author Accepted Manuscript or Proof version this may differ from the final Published version. If citing, it is advised that you check and use the publisher's definitive version.

\section{General rights}

Copyright and moral rights for the publications made accessible in the Research Explorer are retained by the authors and/or other copyright owners and it is a condition of accessing publications that users recognise and abide by the legal requirements associated with these rights.

\section{Takedown policy}

If you believe that this document breaches copyright please refer to the University of Manchester's Takedown Procedures [http://man.ac.uk/04Y6Bo] or contact uml.scholarlycommunications@manchester.ac.uk providing relevant details, so we can investigate your claim.

\section{OPEN ACCESS}


Su, M.N., Wei, L.L., Liang, H.S., Zhu, J.H., Ueda, T., Xing, F. (2020) "Fatigue behaviour and design of corroded reinforced concrete beams intervened by ICCP-SS", Composite Structures, 113295.

Fatigue behaviour and design of corroded reinforced concrete beams intervened by

\title{
ICCP-SS
}

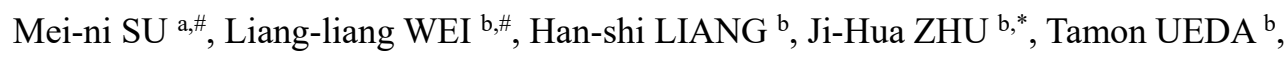

Feng XING ${ }^{\mathrm{b}}$

\author{
${ }^{a}$ School of Mechanical, Aerospace and Civil Engineering, University of Manchester, Manchester, \\ M1 3NJ, UK \\ ${ }^{\mathrm{b}}$ Guangdong Province Key Laboratory of Durability for Marine Civil Engineering, College of Civil \\ and Transportation Engineering, Shenzhen University, Shenzhen, Guangdong 518060, P.R. China \\ E-mail address: meini.su@manchester.ac.uk (M.N. Su), weiliangliang@email.szu.edu.cn (L.L. \\ Wei), lianghanshi@email.szu.edu.cn (H.S. Liang), ueda@szu.edu.cn (T. Ueda),xingf@szu.edu.cn \\ (F. Xing). \\ * Corresponding author: zhujh@szu.edu.cn (J.H. Zhu), Tel./Fax: +86-755-2653-4021 \\ \# The first two authors contribute equally
}

\section{Abstract}

To improve the fatigue resistance of degraded reinforced concrete (RC) beams, the present study employs a dual-functional intervention, impressed current cathodic protection and structural strengthening (ICCP-SS). This paper presents the results of an experimental and analytical study of the fatigue performance of corroded simply supported beams with ICCP-SS intervention. The experimental programme comprises $16 \mathrm{RC}$ beams subjected to accelerated corrosion and ICCP followed by four-point bending tests. The test results show that the corrosion of the steel reinforcements in the cathodically protected beams is effectively prevented. More importantly, the ICCP-SS intervention significantly enhances the fatigue resistance of the flexural members. In 
comparison to those of the corroded beams without any additional measures, the fatigue lives of the treated beams are significantly improved, by as much as $202 \%$. The beams with the ICCP-SS intervention fail due to fatigue fracture of the steel reinforcement followed by a combination of slippage and rupture of the carbon fibre meshes. An amount of ductility is observed at the point of failure of the beams subjected to ICCP-SS intervention. In addition, the experimental results are compared with the predictions of the European and Japanese design codes as well as the Chinese design codes.

Keywords: C-FRCM; Fatigue; Impressed current cathodic protection; Reinforced concrete beam; Structural Strengthening.

\section{Introduction}

Infrastructure such as bridges is continuously subjected to repeated loads from vehicles, which may cause fatigue of the reinforcing bars (re-bar) [1]. Additionally, during the long-term service life of bridges, the corrosion of the steel re-bar in concrete due to the marine environment or de-icing salts is another major problem leading to the early degradation of bridges. The deterioration of reinforced concrete $(\mathrm{RC})$ infrastructure presents severe potential safety issues [2, 3], as tragically demonstrated by the recent collapse of the Morandi Bridge near Genoa in Italy. In addition, a recent increase in traffic volume has highlighted the need for more durable bridges with higher capacities. An effective intervention method for improving the service life of bridges is necessary. Currently, regarding intervention measures, one of the technologies most commonly used to prevent corrosion of steel re-bar in concrete is impressed current cathodic protection (ICCP), whereas one of the most 
popular strengthening technologies for improving the structural capacity of reinforced concrete is fibre reinforced polymer (FRP) strengthening. However, the existing structures subjected to chloride-induced corrosion cannot be systematically repaired simply by using ICCP on its own or the structural strengthening (SS) method on its own because ICCP cannot recover the loading capacity of the degraded structures and SS cannot stop the further corrosion of steel re-bar. Thus, this study proposes the use of the impressed current cathodic protection-structural strengthening (ICCP-SS) intervention method $[4,5]$ to improve the fatigue performance of simply supported corroded RC beams. In the ICCP-SS system, a carbon-fabric reinforced cementitious matrix (CFRCM), which is a composite of two layers of carbon fabric (CF) mesh and cement-based mortar matrix, is pasted to the soffit of beams as both the anode for ICCP and a strengthening material. In recent years, there have been a number of studies on the ICCP-SS intervention method. Carbon fibre reinforced polymer (CFRP) has been found to be a dual-functional material, serving as the structural strengthening layer and the anode for ICCP [6]. For the bonding material, Lambert et al. [7] proposed electrically conductive epoxy, which is conductive pigments in epoxy adhesive, while Su et al. $[5,8]$ developed a high-performance cementitious matrix. Several experimental programmes have been conducted to prove the effectiveness of the ICCP-SS system on degraded structural members subjected to static loads, including RC short columns [4], simply supported beams $[5,7]$ and continuous beams [9]. Experimental results show that the ICCP-SS intervention can not only effectively prevent the corrosion of steel re-bar in concrete but also significantly improve the static structural performance of the degraded structures when the structures are subjected to corrosion. Thus, ICCP-SS provides a potential cost-effective solution to the durability challenges of existing infrastructures. 

structures is subjected to a variety of cycling loads (e.g., wind loads and traffic loads). The degradation of RC beams during cycling loads has been investigated experimentally and numerically in many studies [10-12]. Carpinteri [13] analysed the energy dissipation in RC beams under cyclic loading. Chang et al. [14] investigated the fatigue behaviour of RC beams to discuss the fracture mode, crack growth and distribution, and the relationship between the loading and midspan deflection of the beams under fatigue loading. The final fatigue failure was a result of the gradual damage accumulation of the steel re-bar in the concrete. On top of cycling loads, the corrosion of steel re-bar due to a corrosive environment or the use of sea sand would make the durability of these structures a more critical issue $[15,16]$. The levels of corrosion loss of steel rebar are critical issues [17], and the influence of pit corrosion has also been discussed [18]. Ma et al. [15] conducted experiments on the flexural performance degradation of corroded RC beams under fatigue load. The results indicated that the fatigue fracture of the corroded steel re-bar occurs at the largest corrosion pit location. The fatigue life of the beam at $9.03 \%$ corrosion loss is approximately $65 \%$ of that of the un-corroded beam. studies have investigated the effect of a CFRP sheet/plate on the fatigue behaviour of RC beams was applied to the reinforcing bars of strengthened and un-strengthened beams. The fatigue fracture of the internal steel reinforcement is the dominant factor governing failure in CFRP-strengthened 
loading with different load amplitudes and found that increasing the fatigue load amplitude significantly increased the cracking strain in the CFRP-concrete joint. Al-Rousan et al. [25] studied the effects of various parameters on the fatigue life of RC beams strengthened with CFRP sheets. The results indicated that the applied stress range had the strongest impact on the fatigue life. The fatigue life increased with the number of layers of CFRP and the size of the CFRP-concrete bonding area, both of which facilitate the transfer of stress from the steel re-bar to the CFRP. In addition, the fatigue performance of RC beams strengthened with CFRP under severe environments was considered. Huang et al. [26] studied the effects of temperature on the fatigue behaviour of CFRPstrengthened beams. The results showed that the fatigue life decreased with increasing temperature. Moreover, the failure modes of the strengthened beams shifted from steel yielding to interface debonding as the temperature rose.

However, the studies mentioned above do not cover the fatigue performance of simply supported beams strengthened with C-FRCM composites; furthermore, none of them consider the effect of ICCP on the fatigue performance of simply supported beams. This topic definitely needs investigation. It is well known that the loading response of C-FRCM composites is different from that of CFRP-epoxy resin with more ductility; i.e., a great number of fine cracks occurred during the tensile process, and the final tensile failure was a progressive rupture of the fibre filaments and the slippage of the fibre bundles within the mortar matrix [27, 28]. Therefore, although this study can refer to the fatigue performance of beams strengthened by FRP-epoxy resin, there is still a need to carry out experimental studies to explain the fatigue behaviour of FRCM-strengthened beams.

This paper presents the first investigation of the fatigue performance of simply supported corroded beams with ICCP-SS intervention. In this study, a total of $16 \mathrm{RC}$ beams were prepared and 
subjected to pre-corrosion for 270 days, followed by the bonding of a C-FRCM layer on the soffit of the corroded beam. Afterwards, ICCP was applied to 10 beams for 450 days using the C-FRCM as the anode material. Four-point bending fatigue tests were conducted on the beams to investigate the effects of the protection current density and applied load level on the fatigue life of the beams. The predictions of the fatigue life according to the international design standards - fib Model Code [29] and Japan Society of Civil Engineers (JSCE) Standard Specifications for Concrete Structures [30] as well as the GB 50010 [31] in China were also discussed in comparison to the experimental results.

\section{Experimental programme}

\subsection{Test specimens}

The experimental programme includes a total of $16 \mathrm{RC}$ beams. The dimensions of the beam and configuration of the steel reinforcement are shown in Fig. 1. Detailed information on the specimens and the corresponding labelling system is presented in Table 1. the cement) was added to the concrete mix; the 28-day compressive strength of the concrete was 43.1 MPa. The steel re-bar embedded in the concrete was all HRB400 grade [32]. To simulate the corrosive environment in real applications, after 28 days of curing, the specimens were placed outdoors for 270-day dry-and-wet cycles. After the accelerated corrosion procedure, the soffit of the beam was sandblasted, cleaned, and pre-wet to bond it with the C-FRCM composite. The C-FRCM composite comprised a cementitious matrix [4] and two layers of CF meshes (12,000 filaments for one bundle, mesh size of $10 \mathrm{~mm} \times 10 \mathrm{~mm}$ ). The CF mesh used in this study was from Jiangsu 
Dingfeng Company, with a measured tensile strength of 2125 MPa. The cementitious matrix was developed by Zhu et al. [4] and had a compressive strength of 54.4 MPa and a flexural strength of 7.2 MPa. Please note that strain gauges were attached to the CF meshes at critical locations - the mid-span and loading points of the beams. The C-FRCM composite was cured for 28 days before the application of ICCP to 10 beams for 450 days. As indicated in Table 1, four beams were protected by a current density of $20 \mathrm{~mA} / \mathrm{m}^{2}$, three beams by $60 \mathrm{~mA} / \mathrm{m}^{2}$, and three beams by $100 \mathrm{~mA} / \mathrm{m}^{2}$. The ICCP system has been described in detail in Su et al. [5]. Key electrochemical parameters were measured during the ICCP process.

\subsection{Static and fatigue properties of the steel reinforcement}

The material properties of the steel re-bar were determined by static and fatigue tensile tests. The length of the specimen was $500 \mathrm{~mm}$ for both the static and fatigue tests. For the static loading test, an extensometer with a gauge length of $50 \mathrm{~mm}$ was used to measure the strain of the specimen during loading. The specimen was loaded at $0.2 \mathrm{~mm} / \mathrm{min}$ by displacement control. Regarding the fatigue tests, the distance between the two clamps was equal to $350 \mathrm{~mm}$. The testing frequency was $5 \mathrm{~Hz}$.

The static mechanical properties of the steel in each beam are shown in Table 2. A typical static stress-strain curve is shown in Fig. 2. The experimental results of the stress range of the steel re-bar $(S)$ and the fatigue life $(N)$ are presented in Fig. 3, where $S$ is the fatigue stress range $S=\sigma_{s_{-}} \max$ $\sigma_{s_{-} \min }, \sigma_{s_{-} \max }$ is the upper limit of the fatigue stress, $\sigma_{s_{-} \min }$ is the lower limit of the fatigue stress, and

$151 N$ is the fatigue life. The relationships of the stress range and fatigue life were fitted by linear curves, as shown in Fig. 3 and Eq. (1). The coefficient of determination $\left(\mathrm{R}^{2}\right)$ was 0.925. 


\subsection{Four-point bending tests}

The test configuration of the beam, with a pure bending region of $400 \mathrm{~mm}$ and a shear span of $400 \mathrm{~mm}$, is shown in Fig. 1. To determine the parameters for the fatigue tests, three static four-point bending tests were first performed. The test was displacement-controlled with a loading rate of 0.3 $\mathrm{mm} / \mathrm{min}$. A $10 \mathrm{kN}$ load was applied to the specimen to eliminate the gap between the beam and instrument before the test. During the loading process, the loads, mid-span deflections, and the strains in the steel re-bar, concrete, and CF meshes were measured.

A total of 13 beams were tested by means of fatigue tests under sinusoidal load cycles with a frequency of $5 \mathrm{~Hz}$. The applied load ratio $\left(R_{L}=P_{\min } / P_{\max }\right.$, where $P_{\min }$ is the minimum applied load and $P_{\max }$ is the maximum applied load) that the specimen was subjected to was 0.2 . The applied load levels $\left(S_{L}=P_{\max } / P_{\mathrm{u}}\right.$, where $P_{\mathrm{u}}$ is the ultimate load of the reference beam F0-I0-S) were 0.85 , $0.75,0.65$, and 0.55 . Three cycles of static loading from zero up to $P_{\max }$ were first performed before fatigue loading. In addition, static tests were carried out after specific cycles of fatigue loading to measure the deflections, crack development, and strains of the concrete, steel re-bar, and CF meshes.

\section{Results and discussion for ICCP}

During the 450-day cathodic protection of the beams, it is necessary to collect electrochemical signals such as the feeding voltages and 4-hour decay values to assess the protection effectiveness of the steel re-bar in the concrete, as shown in Fig. 4. The feeding voltages show the change in resistance between the anode and cathode since a constant current was applied. The 4-hour decay value is defined as the difference between the potential of the steel (cathode) measured after a 4- 
174 hour interruption of the current and the instant-off potential, indicating the reduction in corrosion.

175 Fig. 4 (a) shows that as expected, the feeding voltages of the specimens protected by $100 \mathrm{~mA} / \mathrm{m}^{2}$

176 (indicated by the specimen names with I100) are the highest. In comparison, the specimens

177 protected by $20 \mathrm{~mA} / \mathrm{m}^{2}$ (indicated by the specimen names with I20) have the lowest feeding voltages.

178 During the ICCP operation, the feeding voltages are found to be rather stable within the range of 1

$179-4 \mathrm{~V}$, which are rather low values and are safe for access. Fig. 4(b) shows that at the beginning of

180 the ICCP process, the 4-hour decay values of all the specimens are lower than the $100-\mathrm{mV}$ cathodic

181 polarization criterion, which means that the corrosion of the steel is still active outside the immune

182 zones. After 10 days of application of ICCP, the 4-hour decay values of the specimens protected by

$183100 \mathrm{~mA} / \mathrm{m}^{2}$ first reach $100 \mathrm{mV}$, indicating that these specimens have been protected cathodically.

184 Later, the specimens protected by $60 \mathrm{~mA} / \mathrm{m}^{2}$ and by $20 \mathrm{~mA} / \mathrm{m}^{2}$ also generally reach the polarization

185 line after 50 days and 100 days, respectively. This shows that a higher protection current leads to

186 more efficient protection of steel re-bar. During the whole ICCP period, the 4-hour decay values of

187 all specimens increased steadily and finally remained stable at approximately $400 \mathrm{mV}, 200 \mathrm{mV}$, and

$188100 \mathrm{mV}$ for specimens protected at 100,60 , and $20 \mathrm{~mA} / \mathrm{m}^{2}$, respectively. Please note that some

189 minor discrepancies occurred due to variations in the weather and humidity since the specimens

190 were placed outdoors. Even so, it is clear from Fig. 4 that the steel re-bar in beam specimens under

191 ICCP are all well-protected, while a larger protection current leads to more pronounced protection

192 effects.

193 In addition, to better verify the protection effectiveness of ICCP on the steel re-bar in the beam,

194 the steel re-bars were removed from the tested beams after the fatigue tests. These steel re-bars were

195 cleaned according to ASTM G1-03 [33]. The corrosion rate was measured, and the results are 
presented in Table 1. In general, the corrosion rate of the steel re-bar protected by ICCP is lower than that of the unprotected reinforcements.

\section{Results and discussion of the four-point bending tests}

\subsection{Failure modes}

The failure modes of all the tested beams are shown in Table 3, and some typical failure modes are presented in Fig. 5. Under static loads, the un-strengthened unprotected beam (F0-I0-S) fails by the yielding of the steel re-bar and crushing of concrete in the compression zone. The FRCMstrengthened beam (F2-I0-S) and the beam with the ICCP-SS intervention (F2-I60-S) fail by the yielding of the steel re-bar and a combination of slippage between the carbon fibre meshes and cementitious matrix and the partial rupture of carbon fibres. static test cycle and subsequently propagate to the compression zone. The failure mode of the unstrengthened beams (F0-I0-0.65 and F0-I20-0.65) is brittle flexure failure due to fatigue fracture of one tensile steel re-bar. The width and depth of the cracks on the concrete surface are more significant than those on the specimens strengthened with FRCM composite, as shown in Fig. 5. For the 11 FRCM-strengthened beams, including those protected by ICCP and those not, the general failure mode is flexural failure by the fatigue fracture of one or two steel re-bars in the pure bending span, followed by the failure of the FRCM composite due to load redistribution. The stress level of the FRCM composite increases significantly after the fracture of the steel re-bar, leading to a debonding failure at the FRCM/concrete interface (for specimen F2-I0-0.55) (see Fig. 5(b)) or the 
cementitious matrix (for the rest of specimens). As the test continues, the concrete in the compressive zone is finally crushed. It is also observed that the vertical cracks that appear on FRCM-strengthened beams generally are thinner and spaced further apart. Upon the appearance of vertical cracking in the pure bending region, the stress of the tensile longitudinal steel re-bar increases significantly around the crack region. For the non-cathodic protected beams, the reinforcement fractures where corrosion pits are located.

A comparison of the failure modes of the beams strengthened by the FRCM composite and FRPepoxy resin shows that the FRCM-strengthened beams generally fail in a more ductile manner. Before the failure of the FRCM-strengthened beams, more tiny cracks form on the FRCM composite; as the applied load and deflection of the beam increases, one or two cracks exhibited a larger width than the others. A slippage between the carbon fibre meshes and cementitious matrix occurs in these regions. With the accumulation of the slippage, the load resisted by the FRCM composite moves towards the steel re-bar, and the deflection of the beam increases. Upon failure, the re-bar fractures, followed by the fracture of the external carbon fibre meshes in contact with the cementitious matrix. Before fatigue failure, the pronounced deformation of the FRCM-strengthened beams signals the final collapse of the member, which is catastrophic in terms of the safety design considerations. For the FRP-epoxy resin strengthened beams, following the fatigue failure of the re-bar and an extension of the flexural cracks, the CFRP sheets commonly suddenly fail by debonding or fracture under tension $[25,34]$. The FRP-epoxy resin strengthened beams generally fail in a brittle matter without any advance warning.

\subsection{Strain distributions of different components}


strain gauges were attached to these materials at the loading points and mid-span of the beams. Fig. 6(a) shows the strain in the re-bars of an FRCM-strengthened beam (F2-I20-0.65) and a nonstrengthened beam (F0-I20-0.65) after different fatigue cycles. The strain values up to 500 cycles are presented in Fig. 6(a). In the presence of C-FRCM, the deformation of the strengthened beam is smaller, and the strain and stress level of the steel re-bar are clearly lower. As the number of cycles increases, the stress on the steel reinforcement keeps increasing gradually due to the upward movement of the neutral axis of the cracked section. Most of the steel re-bar is found to yield before the tension fracture. Similarly, the stress level of steel re-bar in the FRP-epoxy resin strengthened beams is reduced due to the presence of FRP [25, 34]. The strain development of the concrete in the compression zone at the mid-span of the beam is shown in Fig. 6(b). As expected, a higher load level leads to more considerable strain in the concrete in the compression zone, and the strain in the concrete increases as the fatigue tests continue. Fig. 6(c) shows the strain development in the carbon fibre meshes embedded in the cementitious matrix. The values of the strain gauges decrease due to the stress release after the occurrence of slight deformation and slippage at the CFRP and matrix interface.

\subsection{Hysteretic curves and deflection}

For each specimen, after some fatigue cycles, a static loading test was conducted to generate a loading/unloading curve, as shown in Fig. 7. It can be seen that the area of the load-deflection curve in the first loading/unloading cycle was much larger than that of the following cycles due to the greater energy consumption in the first cycle. The main difference between the first and subsequent cycles is cracking (i.e., crack initiation in the first cycle and crack propagation in the subsequent 
The protection current density and the load level influence the deflection of the beam, as shown

in Fig. 8. In general, under higher protection current, the deflection of the beam is found to be larger,

which is believed to be attributed to the more relaxed mechanical bond between the carbon fibre

meshes and the cementitious matrix. However, this is not true for specimens F2-I20-0.75 and F2-

I60-0.75; unfortunately, the reason for these differences is not yet clear; the possibilities include the

discrepancies associated with concrete materials. As explained by Su et al. [5], an amount of gaseous

yellow liquid appears on the surface of the $\mathrm{CF}$ during the process of ICCP, which may cause the CF

to separate from the concrete interface. The levels of the cyclic loads also affect the deflection in

the component. The experimental results show that a beam subjected to a higher load level deforms

more than the others because under a higher load level, especially the load level of 0.75 , the stress

on the tensile steel re-bar is relatively high, and the steel almost yields, resulting in large deformation

in the steel re-bar and the beam. The deflection of the beam during the cycling load process can be

274 divided into three stages (see Fig. 8 (b)) - in the initial stage of loading (i.e., the first tens of

275 thousands of fatigue cycles), the deflection in the beam increases fast; as the cycling loads continue,

276 the cracks on the concrete become stable, as did the stiffness and deflection of beam; in the final

277 loading stage before failure, the main cracks on the concrete widen and deepen rapidly, so the

278 deflection in beam suddenly increases. In addition, compared to that in the non-strengthened beams,

279 the deflection in the FRCM-strengthened beams is smaller. The development of deflection in simply

280 supported beams strengthened with traditional epoxy resin and FRP plates is close to that in this

281 experiment. The deflection of CFRP-strengthened beams increases almost linearly with the number

282 of cycles when plotted on a log scale until near failure, where it increases rapidly [37, 38]. As 
explained by Song and $\mathrm{Yu}$ [37], the increase in deflection with the cycles is attributed to the degradation of the constituent material properties and the increase in the depth of the flexural cracks with repeated loading.

\subsection{Fatigue life}

The fatigue lives of 13 beams under fatigue loading tests are summarized in Table 4 and Fig.

9. Under the same load level and protection current density (F0-I0-0.65 versus F2-I0-0.65; F0-I200.65 versus F2-I20-0.65), the fatigue lives of the strengthened beams are approximately $250 \%$ of those of the non-strengthened beams. The improvement in the fatigue behaviour in the presence of the C-FRCM composite is pronounced since the C-FRCM composite decreases the stress level of the steel re-bar.

The relation between the load level and the fatigue life of the beams is shown in Fig. 9(a).

The results indicate that the fatigue life is reduced with increasing load level. For example, when the protection current density is $20 \mathrm{~mA} / \mathrm{mm}^{2}$, the fatigue life values of the strengthened beams at load ratios of $0.55,0.65$ and 0.75 are $111.3,52.8$ and $19.4 \times 10^{4}$ cycles, respectively. It is also found that the fatigue life of the RC beams is largely dependent on the steel re-bar. As shown in Table 5, the fatigue cycles of the beam obtained from the four-point bending tests are generally close to the fatigue cycles derived from the stress level of the re-bar. It is therefore recommended that one of the criteria for the fatigue design of FRCM-strengthened beams should be the limit of the stress level of the steel re-bar.

The relation between the protection current density and the fatigue life of the beam is shown in Fig. 9(b). Under the same applied load level, the fatigue lives of the beams cathodically protected by different currents are similar. As illustrated in Section 3, the steel re-bar of all the cathodically 
protected beams are found to be protected from corrosion well; therefore, the corrosion conditions of the cathodically protected beams are similar. In addition, although the applied current causes anode polarization at the C-FRCM interface, this effect has not caused significant degradation of the C-FRCM anode; therefore, the strengthening performance of the C-FRCM composite is similar as the applied currents varied from $20 \mathrm{~mA} / \mathrm{m}^{2}$ to $100 \mathrm{~mA} / \mathrm{m}^{2}$.

Compared to those of specimens F0-I0-0.65 and F0-I20-0.65, the fatigue lives of specimens F2-I0-0.65 and F2-I20-0.65 increase by $150 \%$ and $156 \%$, respectively. This is due to the contribution of FRCM to the reduction in the steel stress during the cycling loads. However, the improvement in the fatigue life performance of FRCM-strengthened beams is not very prominent, as expected, although the percentage of improvement can be larger when the reinforcement ratio of the beams is smaller. The possible explanation for this result is the premature cracking of the FRCM at the beginning of cycling loading followed by fabric slippage, which results in the limitation of reduction in the steel stress. In future studies, to improve the contribution of the FRCM to the fatigue performance of concrete structures under flexure, the ductility of the FRCM composites can be enhanced. Leung et al. [39] concluded that the high ductility and capability to form multiple fine cracks of engineered cementitious composites (ECCs) are responsible for an impressive improvement in the fatigue performance of RC beams. It is believed that high ductility and multiple fine cracks can help release the energy in the process of cycling loading on concrete structures. 37, 40-43] are also collected (see Table 6) for comparison with the fatigue behaviour of the FRCMstrengthened beams generated in this study (see Table 5), as shown in Fig. 10. Under a similar stress 

0.36) was $2 \times 10^{6}$ cycles, that of the beam tested by Barnes et al. [23] (load level of 0.32) was 1.89 $\times 10^{6}$ cycles, and that of beam F2-I20-0.55 tested in this study could reach $1.11 \times 10^{6}$ cycles. The S$\mathrm{N}$ relationship of the specimens in which steel reinforcement fatigue fracture occurs is more or less the same despite the differences in the strengthening method (FRP external bonding, FRCM overlaying). The corrosion of steel re-bar in concrete has specific influences on the fatigue life of RC beams. The fatigue life decreased from 1346 to 304 thousand cycles at the identical fatigue load ratio of $38.9 \%$ when the corrosion of steel re-bar increased from $8.3 \%$ to $16.7 \%$ (i.e., the average mass loss of steel) [37]. In contrast, the ICCP-SS intervention method could be helpful for controlling the corrosion of steel re-bar, demonstrated by the fact that the fatigue life of beam F2I20-0.55 reaches more than 1000-thousand cycles at the fatigue load ratio of 55\%.

\section{Comparison with design predictions} are used to predict the fatigue life of the beams considered in this study. The predicted results are compared with the experimental fatigue life results in the present paper to assess the accuracy of the existing standards for the fatigue of beams repaired by the ICCP-SS intervention method. The experiment in the present paper uses a single load level, and the fatigue damage of the specimens is controlled by the steel re-bar. All the safety factors are set to be unity for comparison purposes. 
The fatigue design procedure is codified in Section 7.4.1 of the fib Model Code [29] through semi-empirical design curves based on existing fatigue test data. The fatigue design in this code is applicable to non-low cycle fatigue members with fatigue lives greater than $10^{6}$ cycles. When the test is a single load level, the failure mode is controlled by the fatigue life of the steel re-bar:

$$
\left(\Delta \sigma_{R s k}\right)^{m} N^{*}=\left(\Delta \sigma_{E s}\right)^{m} N_{f}
$$

When the diameter of the steel re-bar $\phi \leq 16 \mathrm{~mm}, \Delta \sigma_{R s k}=160 \mathrm{MPa}$ at $N^{*}=10^{6}$, and the stress exponent $m=5$, while $\Delta \sigma_{R s k}=95 \mathrm{MPa}$ at $10^{8}$ cycles, and the stress exponent $m=9$; therefore, the fatigue life $N_{f}$ can be obtained based on the relevant stress range $\Delta \sigma_{E s}=\sigma_{\max }-\sigma_{\min }$,

\subsection{JSCE Standard Specifications} calculation is as follows:

$$
f_{s r d}=190 \frac{10^{a}}{N^{k}}\left(1-\frac{\sigma_{s p}}{f_{u d}}\right) / \gamma_{s}
$$

When $\mathrm{N} \leqslant 2 \times 10^{6}, a$ and $k$ are determined by the following formula:

$$
\begin{aligned}
& a=k_{0 f}(0.81-0.003 \phi) \\
& k=0.12
\end{aligned}
$$


50010-2010 [31] recommends the limit stress ranges of steel reinforcement in Section 4.2.6, as shown in Table 7. When the stress range of steel reinforcements is within this range, RC structures are expected to have a fatigue life greater than $2 \times 10^{6}$ cycles. However, GB 50010-2010 [31] does not provide design equations for predicting the fatigue life of $\mathrm{RC}$ structures when the stress range of the reinforcements exceeds the values given in Table 7. Two types of steel reinforcements were investigated to obtain the S-N relationships, i.e., HRB 335 and HRB 400 hot-rolled ribbed bars.

\section{4 Result comparisons}

The fatigue lives of the steel reinforcements obtained from fatigue tests (see Fig. 3) are compared to the predictions by fib [29], JSCE [30] and GB 50010 [31], as shown in Fig. 11, where the test data are the measured stress range. Note that GB 50010 only provides the limit stress range of steel under fatigue when it sustains more than $2 \times 10^{6}$ fatigue cycles. When the fatigue life reaches the specified number of cycles at $2 \times 10^{6}$, the maximum stress predicted by JSCE is $181 \mathrm{MPa}$, followed by $S=179 \mathrm{MPa}$ based on the proposed model (i.e., Eq. (1) in the present paper). In Table

7, it can be found that $S=156 \mathrm{MPa}$ per GB 50010. The result predicted by the fib Model Code has the lowest limit stress range of $147 \mathrm{MPa}$. To consider a possible long cycle at $2 \times 10^{7}$, the predicted limit stress values of steel based on the proposed model in this paper and fib Model Code are 128 MPa and $123 \mathrm{MPa}$, respectively. In addition, as shown in Table 8, the nominal yielding and ultimate strength of the HRB 335 steel are $335 \mathrm{MPa}$ and $455 \mathrm{MPa}$, respectively, and those of the HRB 400 steel are $400 \mathrm{MPa}$ and $540 \mathrm{MPa}$, respectively [31]. The diameter of the steel re-bar is taken as 12 $\mathrm{mm}$. The fatigue lives of the two kinds of steel re-bar can be predicted by the fib model code using Eq. (2) and by the JSCE Standard Specifications using Eq. (3). It is found that the prediction results 
the fib Model Code are more sensitive to the type steel reinforcement than those of GB and JSCE.

The key results obtained from fatigue tests are presented in Table 4, and the fatigue lives predicted by fib [29], JSCE [30], and the S-N curve of steel reinforcement (see Fig. 3) are summarized in Fig. 12 and Table 5. The calculation was carried out based on both the strain value obtained from the beam theory (i.e., the plane-remain-in-plane hypothesis) and the strain value obtained from the strain gauges in the tests. Fig. 12 indicates that the predictions based on the measured strain of the steel re-bar are generally more accurate and consistent than those based on beam theory. All three design methods are generally conservative when following beam theory. Among the three design methods, the predictions by the steel S-N curve are the closest to the test results, followed by the predictions per the fib Model Code [29], while the JSCE Standard Specifications [30] provide the most conservative predictions. It is indicated that the fatigue lives of these beams are generally governed by the fatigue life of the steel reinforcements. When using the fib Model Code for the design of fatigue beams, the predicted fatigue life is lower than the experimental results regardless of whether the predictions are carried out based on beam theory or the measured strain values, except for specimen F2-I0-0.75. Regarding the JSCE Standard Specifications [30], the predicted fatigue life is significantly conservative compared to the measured fatigue life from tests when the load ratio is 0.75 , and the stress level of the re-bar is near the yielding level (more than $90 \%$ of the yield). JSCE seems unsuitable for the fatigue design of beams when 407 the steel re-bar has almost yielded. For load ratios of 0.65 and 0.55 , although the predicted fatigue life is generally conservative, it is not far from the experimental results except for those of specimen F0-I20-0.65. In the fib Model Code [29], the diameter of the steel reinforcement is taken into consideration, while the JSCE Standard Specifications considers the ultimate tensile strength of the 
steel reinforcement. It is possible to explain the deviation between the fatigue lives of the experimental and predicted results.

The key differences associated with the beams considered in this study are that the beams have been subjected to accelerated corrosion and ICCP treatment. The results show that for beams with corroded steel reinforcements, the current prediction formulas of the fatigue life can be adopted when the corrosion degree of the steel is lower than 5\%. In Table 4, both the maximum stress and the stress range of the steel in beam F2-I20-0.55 are higher than those in beam F2-I0-0.55. Similarly, the stress of the steel in the beams with ICCP-SS intervention is also slightly higher than that in the solely strengthened beams at the applied load levels of 0.65 and 0.75 . Accordingly, compared with the those of the beams strengthened by C-FRCM, the counterpart beams subjected to ICCP treatment have comparable steel stress conditions, resulting in the similar fatigue lives of the treated beams. This result might be due to the negligible corrosion of the steel in the concrete before application of the ICCP treatment. However, for the ICCP-SS-treated beams, the C-FRCM layer is degraded at the interface after cathodic protection, resulting in an unmatured failure of the C-FRCM layer, and more stress is thereafter transferred to the steel reinforcement. Thus, the actual strain distribution might not satisfy the linear proportional relationship assumed by the plane-remain-plane hypothesis. The difference between the experimental and predicted results could be partly attributed to the discreteness of the measured strain values of the re-bars due to the stress concentrations at the corrosion pits.

\section{Conclusions}

A total of 16 simply supported beams were tested under static and cycling loads. Before fourpoint bending tests, these beams were subjected to 150-day accelerated corrosion and were repaired 
by ICCP-SS with 450-day cathodic protection. The test results show that corrosion of the steel rebars in the cathodically protected beams is effectively prevented and that ICCP-SS intervention can significantly enhance the fatigue resistance of flexural members. Under static load, the failure mode of the ICCP-SS-treated beams is the yielding of the steel reinforcement followed by a combination of the slippage and partial rupture of the carbon fibre meshes. During cyclic loading, the crack width and spacing on the concrete surface are smaller for C-FRCM-strengthened beams than for nonstrengthened beams for the same load. The stress level of the steel tension reinforcement generally increases as the neutral axis of the cross-section moves up due to the development of cracks in the concrete. The failure mode of un-strengthened beams is brittle flexure failure due to fatigue fracture of one tensile steel re-bar; the general failure mode of the FRCM-strengthened beams is flexural failure by fatigue fracture of one or two steel re-bars in the pure bending span, followed by failure of the FRCM composite due to load redistribution. from the stress level of the reinforcing bars using the S-N relationship of the reinforcing bars taken

447 from the beam repaired by ICCP-SS. The experimental results are also compared with the predictions by the JSCE and fib design codes. In general, both design standards underestimate the fatigue lives of ICCP-SS beams because the S-N relationships provided by the standards underestimate the fatigue lives of the reinforcing bars in the beams; the predictions calculated based on the measured steel strain are closer to the experimental results.

\section{Notations}


$\sigma_{s_{-} \max }=$ upper limit of the fatigue stress of steel in the tensile loading tests;

$\sigma_{s_{-} \min }=$ lower limit of the fatigue stress of steel in the tensile loading tests;

$457 \quad N=$ fatigue life of steel in the tensile loading tests;

$R_{L}=$ applied load ratio of beams under cycling loads;

$P_{\max }=$ maximum applied load of beams;

$P_{\min }=$ minimum applied load of beams;

$S_{L}=$ applied stress level of beams under cycling loads;

$P_{\mathrm{u}}=$ ultimate load of the reference beam F0-I0-S;

$\Delta \sigma_{R s k}=$ stress range relevant to $N^{*}$ cycles;

$m=$ stress exponent in the characteristic fatigue strength function;

$N^{*}=$ characteristic number of cycles;

$\Delta \sigma_{E s}=$ steel stress range under the acting loads;

$\sigma_{\max }=$ maximum steel stress corresponding to the maximum applied load in the fatigue tests of beams; $\sigma_{\min }=$ minimum steel stress corresponding to the minimum applied load in the fatigue tests of beams; $N_{f}=$ predicted fatigue life in the stress range $\Delta \sigma_{E s} ;$ $f_{s r d}=$ design fatigue strength of a deformed bar; $f_{u d}=$ design tensile strength of steel re-bar;

$473 \sigma_{s p}=$ stress in the deformed bar due to permanent load, which is assumed here to be as the minimum

$474 \quad$ stress during the cyclic loading;

$475 \gamma_{s}=$ material factor of the steel re-bar, which is taken here as 1.0; $a=\mathrm{a}$ factor depending on the shape of the lug and the diameter of the steel re-bar; 
$\phi=$ diameter of the steel re-bar (units: $\mathrm{mm}$ );

$479 i=$ protection current density $\left(\mathrm{mA} / \mathrm{m}^{2}\right)$;

480 $\rho=$ corrosion degree $(\%)$.

481

Declarations of interest relationships that could have appeared to influence the work reported in this paper.

Data availability statement

The raw/processed data required to reproduce these findings cannot be shared at this time as the data also forms part of an ongoing study.

\section{Acknowledgements}

We would like to thank the support from the Key-Area Research and Development Program of Guangdong Province (2019B111107002), the National Key Research and Development Program of

$494(51538007 / 51778370 / 51861165204)$, the Natural Science Foundation of Guangdong 495 (2017B030311004), and the Shenzhen Science and Technology Project

\section{References}

498 [1] Pimentel M, Brühwiler E, Figueiras J. Fatigue life of short-span reinforced concrete railway 
bridges. Struct Concr 2008;9:215-22.

500 [2] Al-Hammoud R, Soudki K, Topper TH. Fatigue flexural behavior of corroded reinforced concrete beams repaired with CFRP sheets. J Compos Constr 2010;15:42-51.

502 [3] Rteil A, Soudki K, Topper T. Mechanics of bond under repeated loading. Constr Build Mater 2011;25:2822-7.

504 [4] Zhu J, Su M, Huang J, Ueda T, Xing F. The ICCP-SS technique for retrofitting reinforced concrete compressive members subjected to corrosion. Constr Build Mater 2018;167:669-

[5] Su M, Wei L, Zeng Z, Ueda T, Xing F, Zhu J-H. A solution for sea-sand reinforced concrete

[6] Zhu J-H, Wei L, Moahmoud H, Redaelli E, Xing F, Bertolini L. Investigation on CFRP as

[7] Lambert P, Van Nguyen C, Mangat PS, O’Flaherty FJ, Jones G. Dual function carbon fibre dual-functional material in chloride-contaminated solutions. Constr Build Mater

[10] Bruno D, Olivito RS, Spadea G. Fracture in reinforced concrete beams under repeated loads.

[11] Kwak H-G, Kim S-P. Nonlinear analysis of RC beam subject to cyclic loading. J Struct Eng

[12] Carpinteri A, Spagnoli A, Vantadori S. Mechanical damage of ordinary or prestressed 1991;39:177-84. 
[14] Chang D-I, Chai W-K. A study on the fatigue strength behavior of reinforced concrete structures. Int J Press Vessel Pip 1989;40:51-75.

[15] Ma Y, Wang G, Su X, Wang L, Zhang J. Experimental and modelling of the flexural performance degradation of corroded RC beams under fatigue load. Constr Build Mater 2018;191:994-1003.

[16] Wu J, Diao B, Xu J, Zhang R, Zhang W. Effects of the reinforcement ratio and chloride

[17] Azad AK, Ahmad S, Azher SA. Residual strength of corrosion-damaged reinforced concrete beams. ACI Mater J 2007;104:40.

[18] Guo Z, Ma Y, Wang L, Zhang J. Modelling guidelines for corrosion-fatigue life prediction of concrete bridges: Considering corrosion pit as a notch or crack. Eng Fail Anal

[19] Brena SF, Benouaich MA, Kreger ME, Wood SL. Fatigue tests of reinforced concrete beams

[20] Aidoo J, Harries KA, Petrou MF. Full-scale experimental investigation of repair of

[22] Harries KA, Reeve B, Zorn A. Experimental evaluation of factors affecting monotonic and

[23] Barnes RA, Mays GC. Fatigue performance of concrete beams strengthened with CFRP

[24] Gheorghiu C, Labossiere P, Proulx J. Response of CFRP-strengthened beams under fatigue

[25] Al-Rousan R, Issa M. Fatigue performance of reinforced concrete beams strengthened with 
2011;34:708-16.

[27] Arboleda D, Carozzi FG, Nanni A, Poggi C. Testing procedures for the uniaxial tensile characterization of fabric-reinforced cementitious matrix composites. J Compos Constr 2015;20:4015063.

[28] Wei L, Zhu J-H, Ueda T, Su M, Liu J, Liu W, et al. Tensile behaviour of carbon fabric reinforced cementitious matrix composites as both strengthening and anode materials. Compos Struct 2020;234. https://doi.org/10.1016/j.compstruct.2019.111675.

[29] fib. fib Model Code for Concrete Structures. Berlin, Germany: Ernst \& Sohn, Wiley, 2013. Print. 2010.

[30] JSCE. Standard Specifications for Concrete Structures - Design. Japan Society of Civil Engineers, JSCE Guidelines for Concrete No. 15. 2007.

[31] GB 50010. Code for design of concrete structures. Beijing, China: China Building Industry Press. 2010.

[32] GB/T 1499.2. Steel for the reinforcement in concrete - Part 2: Ribbed bars, NEQ. Beijing, China: Standards Press of China. 2018.

[33] ASTM G1-03(2017). Standard Practice for Preparing, Cleaning, and Evaluating Corrosion Test Specimens. ASTM International, West Conshohocken, PA. 2017.

[34] Al-Hammoud R, Soudki K, Topper TH. Bond analysis of corroded reinforced concrete beams under monotonic and fatigue loads. Cem Concr Compos 2010;32:194-203.

[35] Dong JF, Wang QY, Guan ZW. Structural behaviour of RC beams externally strengthened with FRP sheets under fatigue and monotonic loading. Eng Struct 2012;41:24-33.

[36] Katakalos K, Papakonstantinou CG. Fatigue of reinforced concrete beams strengthened with steel-reinforced inorganic polymers. J Compos Constr 2009;13:103-12.

[37] Song L, Yu Z. Fatigue performance of corroded reinforced concrete beams strengthened with CFRP sheets. Constr Build Mater 2015;90:99-109.

[38] Ferrier E, Bigaud D, Clement JC, Hamelin P. Fatigue-loading effect on RC beams strengthened with externally bonded FRP. Constr Build Mater 2011;25:539-46.

[39] Leung CKY, Cheung YN, Zhang J. Fatigue enhancement of concrete beam with ECC layer. Cem Concr Res 2007;37:743-50. https://doi.org/10.1016/j.cemconres.2007.01.015.

[40] Papakonstantinou CG, Petrou MF, Harries KA. Fatigue behavior of RC beams strengthened 
with GFRP sheets. J Compos Constr 2001;5:246-53.

590 [41] Masoud S, Soudki K, Topper T. Postrepair fatigue performance of FRP-repaired corroded RC beams: Experimental and analytical investigation. J Compos Constr 2005;9:441-9.

[42] Charalambidi BG, Rousakis TC, Karabinis AI. Fatigue behavior of large-scale reinforced concrete beams strengthened in flexure with fiber-reinforced polymer laminates. J Compos Constr 2016;20. https://doi.org/10.1061/(ASCE)CC.1943-5614.0000689.

[43] Aidoo J, Harries KA, Petrou MF. Fatigue behavior of carbon fiber reinforced polymerstrengthened reinforced concrete bridge girders. J Compos Constr 2004;8:501-9. https://doi.org/10.1061/(ASCE)1090-0268(2004)8:6(501). 
599 Fig. 1. Detailed dimensions and test set-up of beam specimens (all dimensions in $\mathrm{mm}$ ).

600 Fig. 2. Typical stress-strain curve of reinforcement obtained from static tensile test.

601 Fig. 3. S-N fitting curve for reinforcement fatigue test results.

602 Fig. 4. Electrochemical parameters of the beam measured during ICCP protection: (a) Feeding 603 voltage; (b) 4-hour decay potential.

604 Fig. 5. Failure modes of beams under fatigue loading: (a) Fatigue failure of non-strengthened beam 605 (F0-I0-S); (b) Fatigue failure of strengthened beam - debonding between the CF meshes and 606 cementitious matrix after reinforcement fracture (F2-I0-0.55); (c) Slippage and partial fracture of 607 CF meshes after reinforcement fracture.

608 Fig. 6. Strain of reinforcement in fatigue loading: (a) Steel reinforcement; (b) Concrete; (c) Carbon 609 fibre meshes.

610 Fig. 7. Typical load-deflection curves from fatigue tests: (a) F2-I20-0.55; (b) F2-I20-0.75.

611 Fig. 8. Deflection of beams after different fatigue cycles: (a) Effects of current density; (b) Effects 612 of load level.

613 Fig. 9. Relationship between fatigue life and current density in ICCP and load level during cycling 614 loads: (a) Effects of load level; (b) Effects of current density.

615 Fig. 10. Comparison results of S-N relation between FRP system and FRCM in this paper.

616 Fig. 11. Comparison results of fatigue life of steel in tension between the proposed model and 617 international codes.

618 Fig. 12. Comparison results of fatigue life of beams: (a) Comparison of fatigue life based on the 619 steel stress calculated from the beam theory; (b) Comparison of fatigue life based on the steel stress 620 calculated from the measured strain of steel reinforcement. 


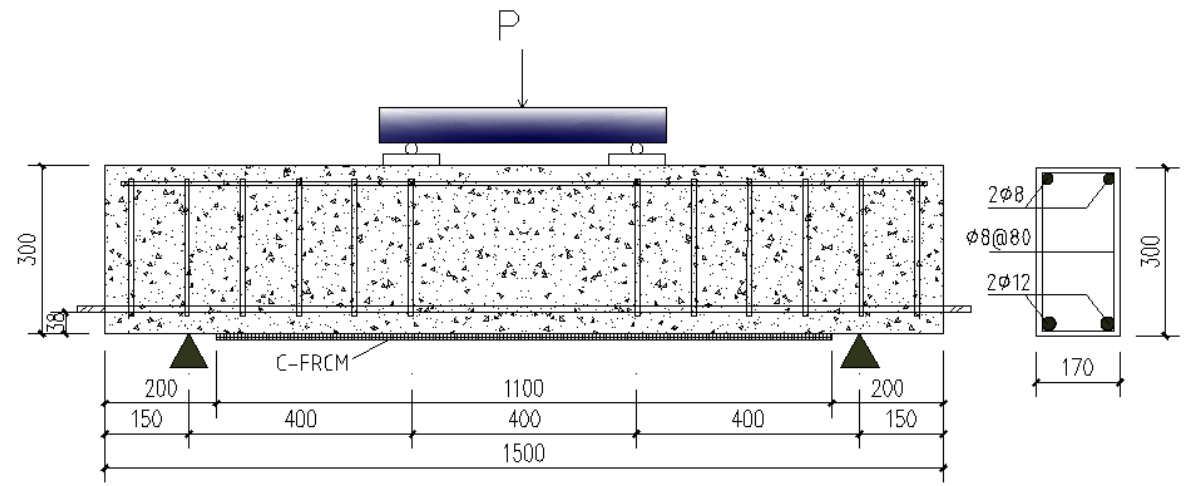

Fig. 1. Detailed dimensions and test set-up of beam specimens (all dimensions in mm).

623

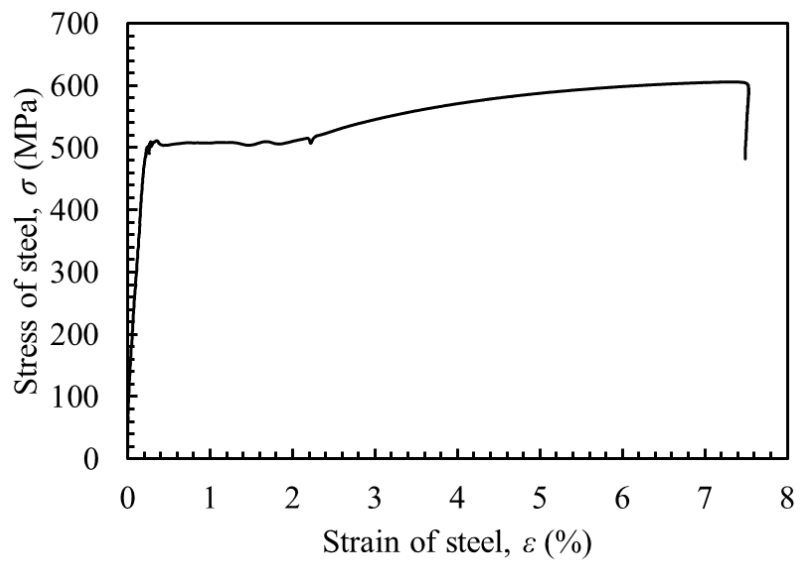

Fig. 2. Typical stress-strain curve of reinforcement obtained from static tensile test.

626

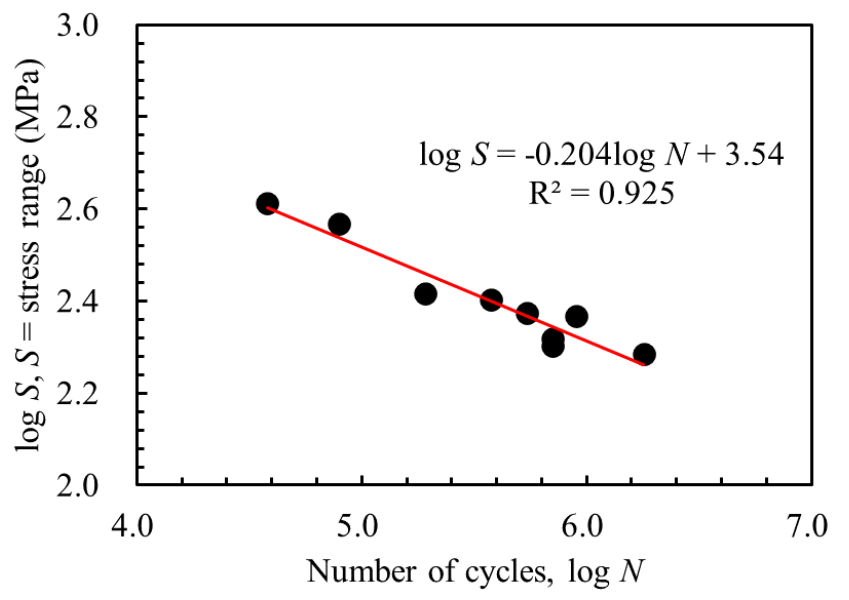

Fig. 3. S-N fitting curve for reinforcement fatigue test results. 


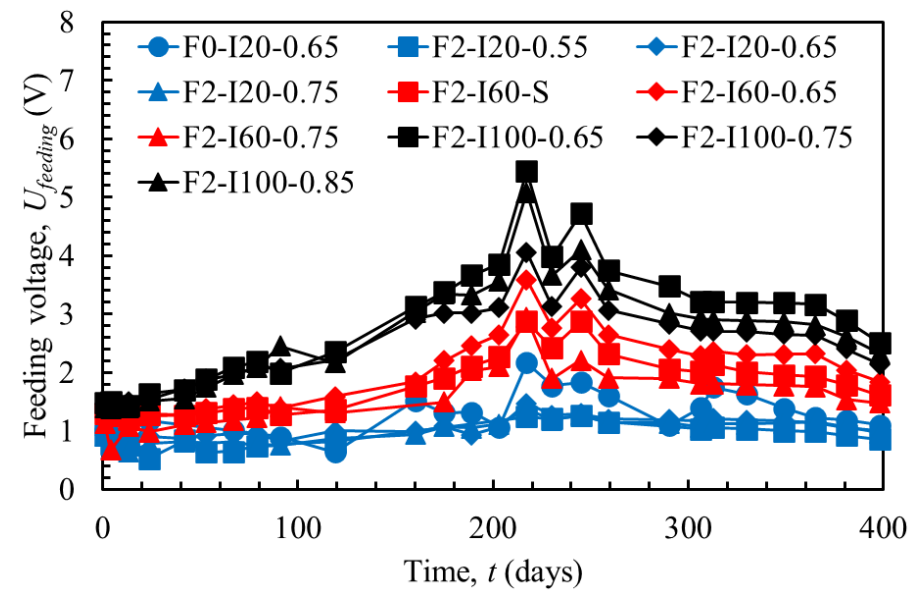

(a) Feeding voltage

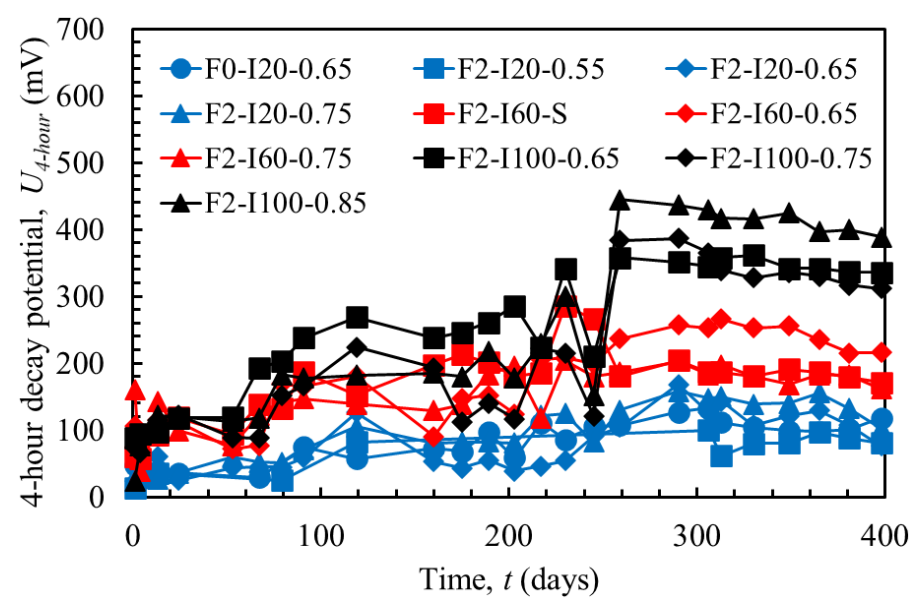

(b) 4-hour decay potential

Fig. 4. Electrochemical parameters of the beam measured during ICCP protection. 


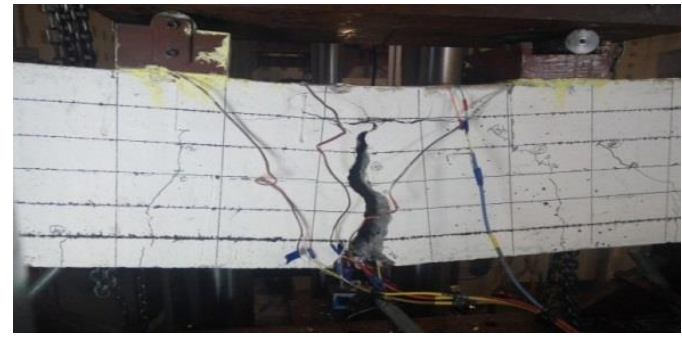

(a) Fatigue failure of non-strengthened beam (F0-I0-S)

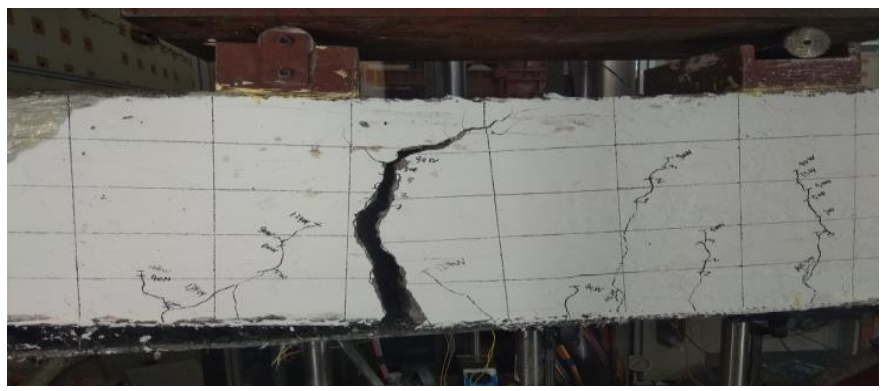

637 (b) Fatigue failure of strengthened beam - debonding between the CF meshes and cementitious

matrix after reinforcement fracture (F2-I0-0.55)

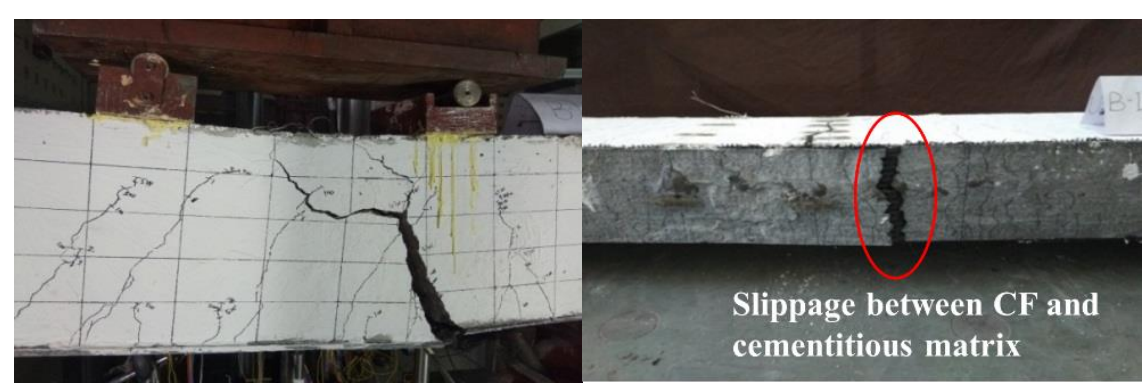

(c) Slippage and partial fracture of CF meshes after reinforcement fracture

Fig. 5. Failure modes of beams under fatigue loading. 
642

643

644

645

646

647

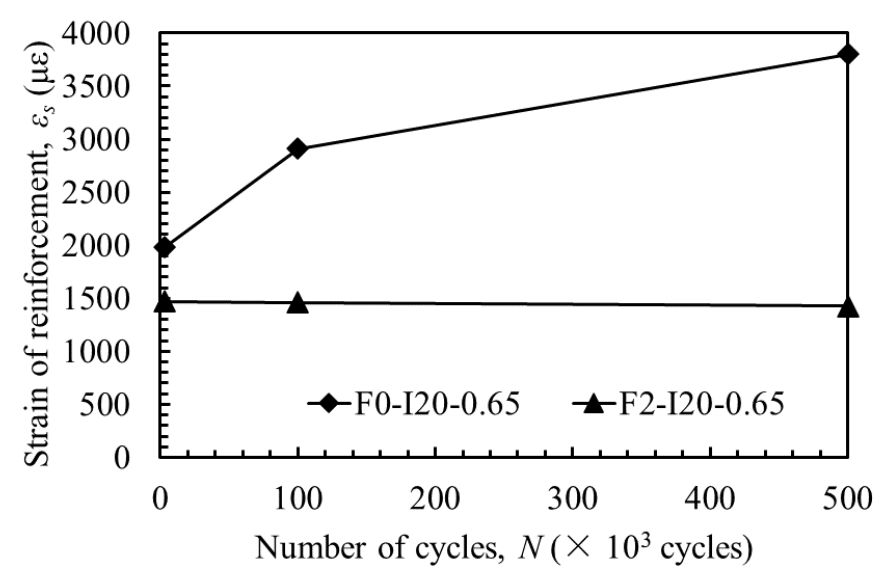

(a) Steel reinforcement

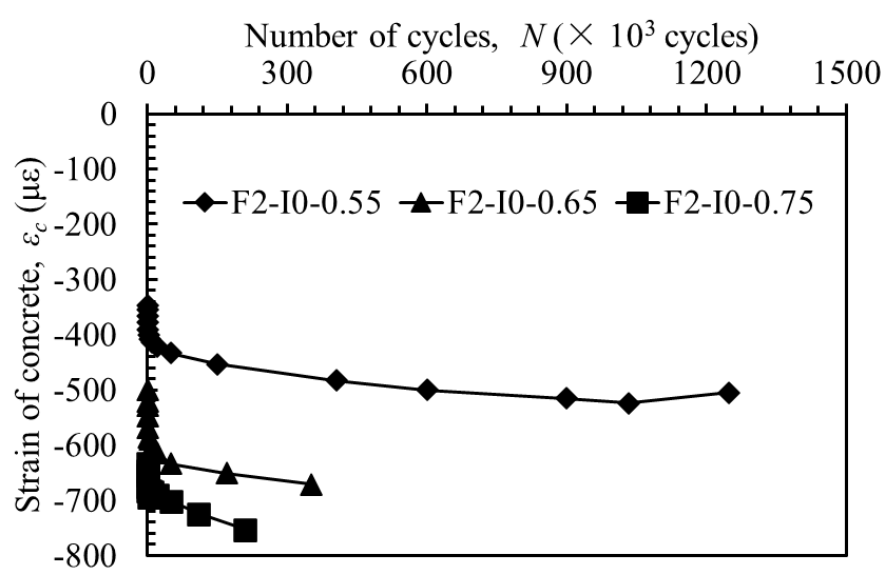

(b) Concrete

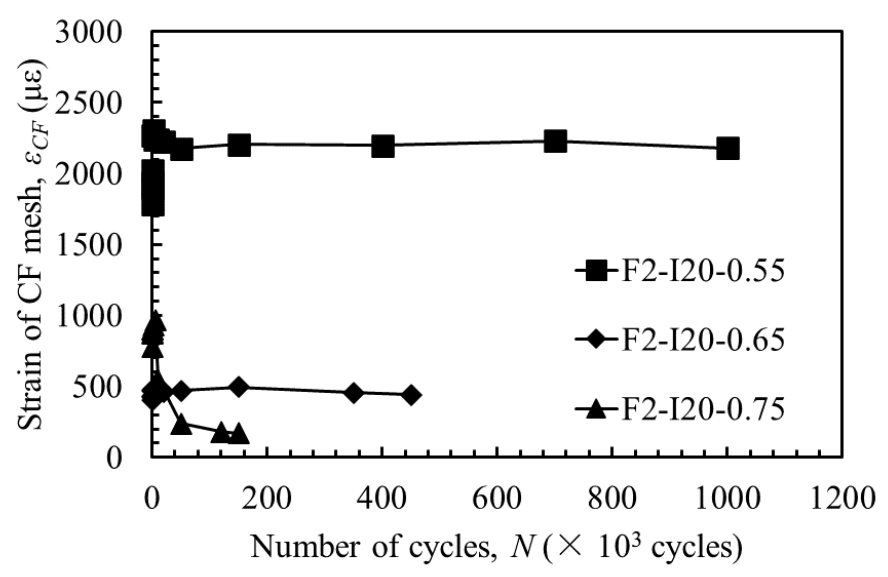

(c) Carbon fibre meshes

Fig. 6. Strain of reinforcement in fatigue loading. 


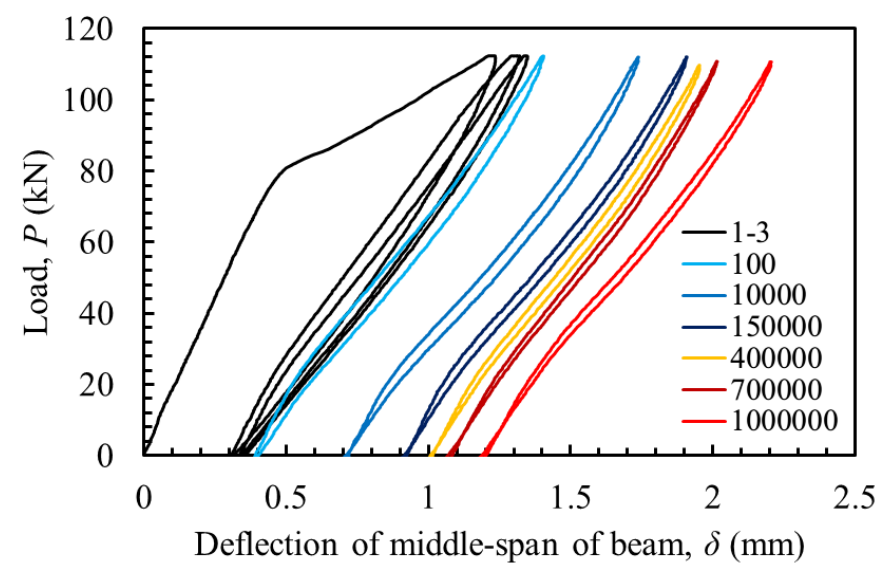

(a) F2-I20-0.55

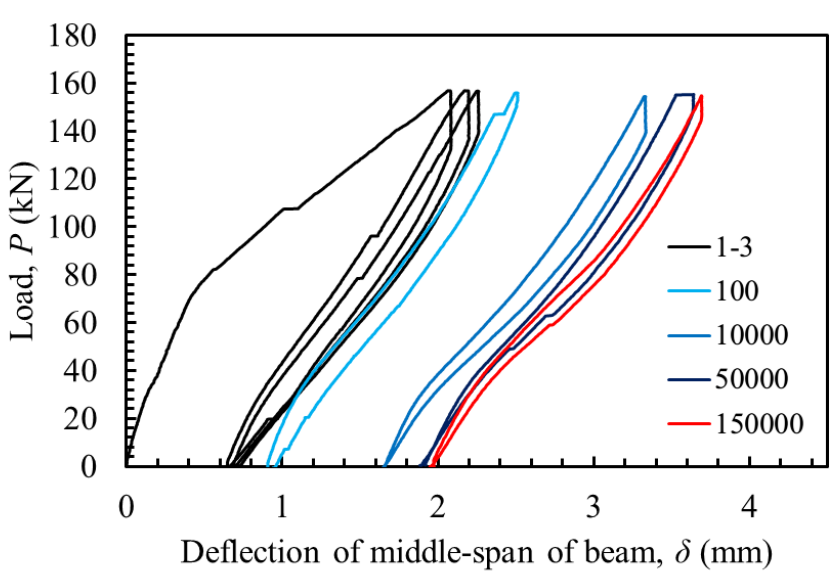

651

(b) F2-I20-0.75

Fig. 7. Typical load-deflection curves from fatigue tests. 

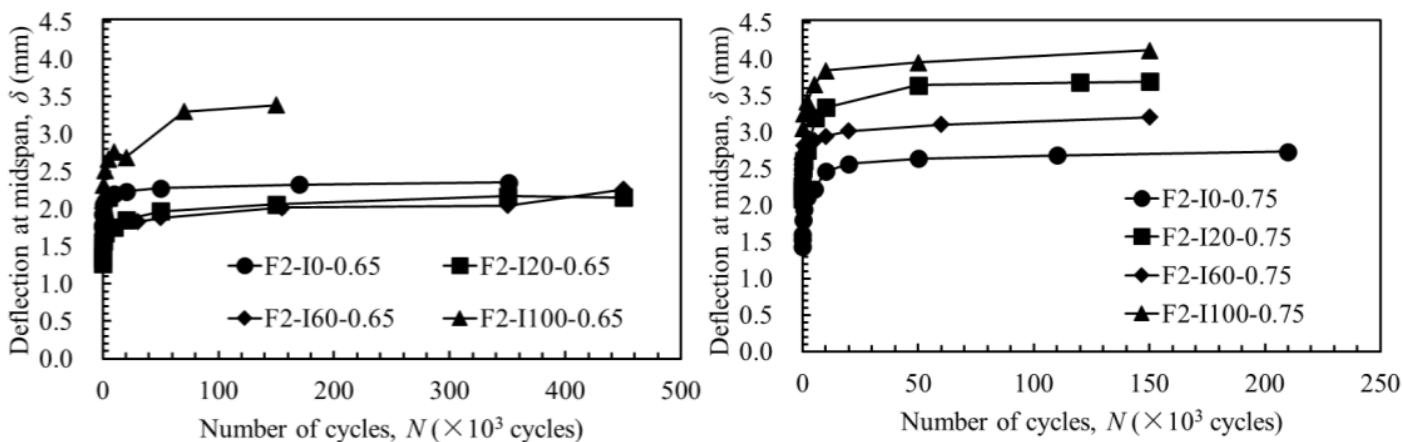

654

(a) Effects of current density
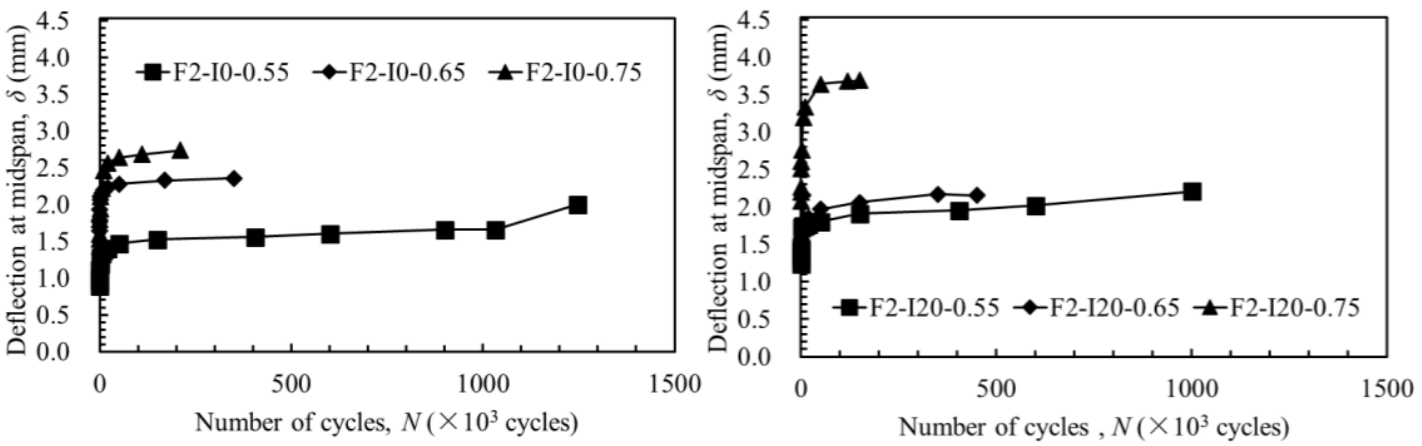

656

(b) Effects of load level

658

Fig. 8. Deflection of beams after different fatigue cycles. 


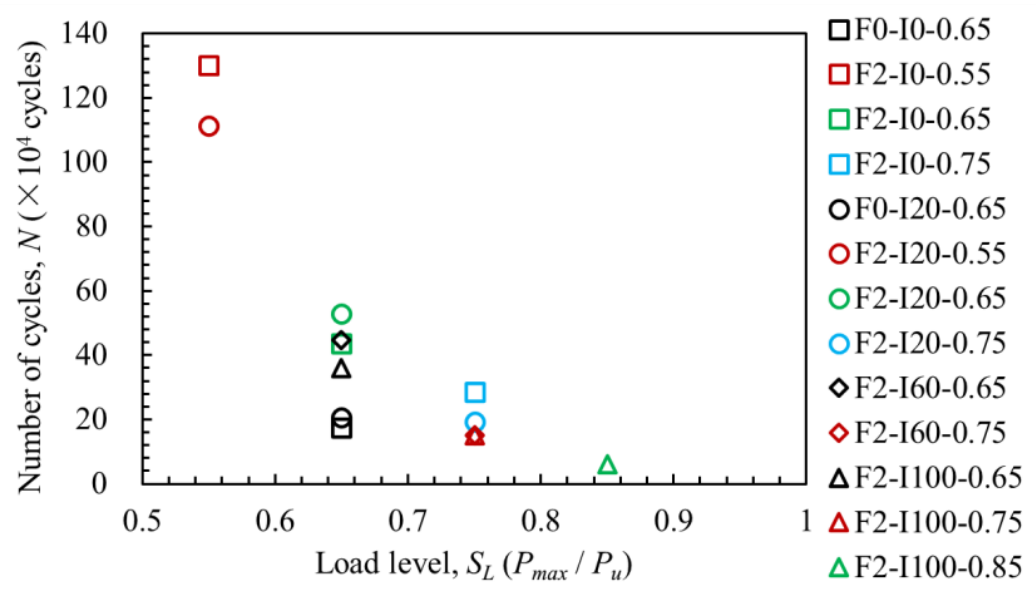

660

(a) Effects of load level

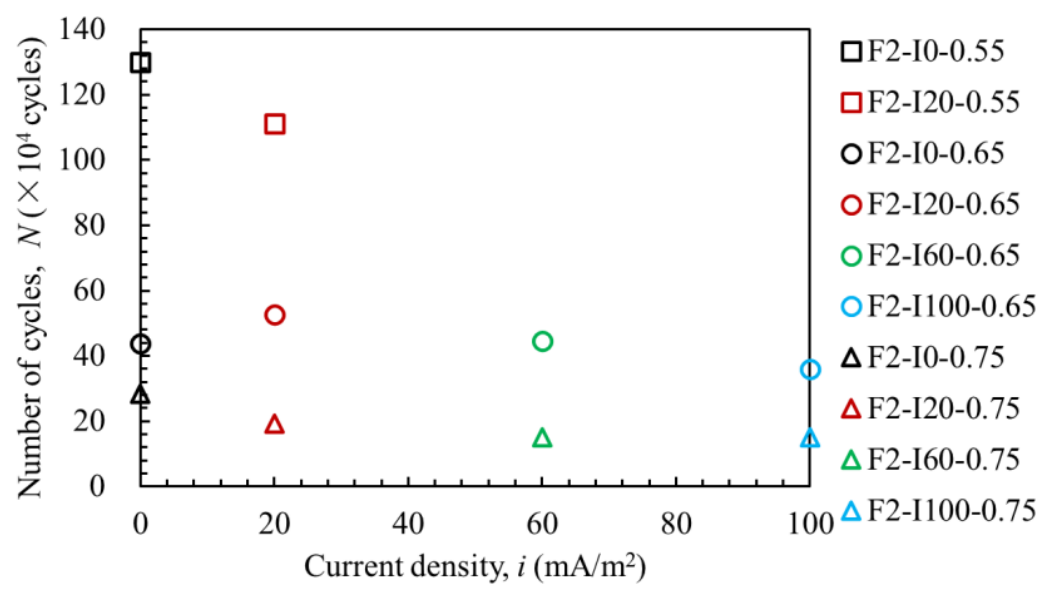

661

(b) Effects of current density

663 Fig. 9. Relationship between fatigue life and load level during cycling loads and current density in 


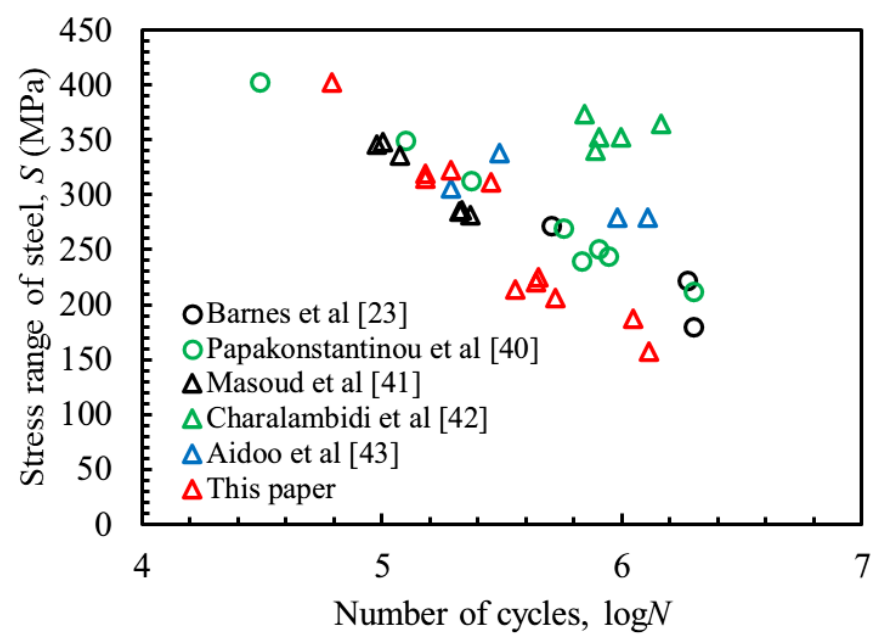

Fig. 10. Comparison results of S-N relation between FRP system and FRCM in this paper.

667

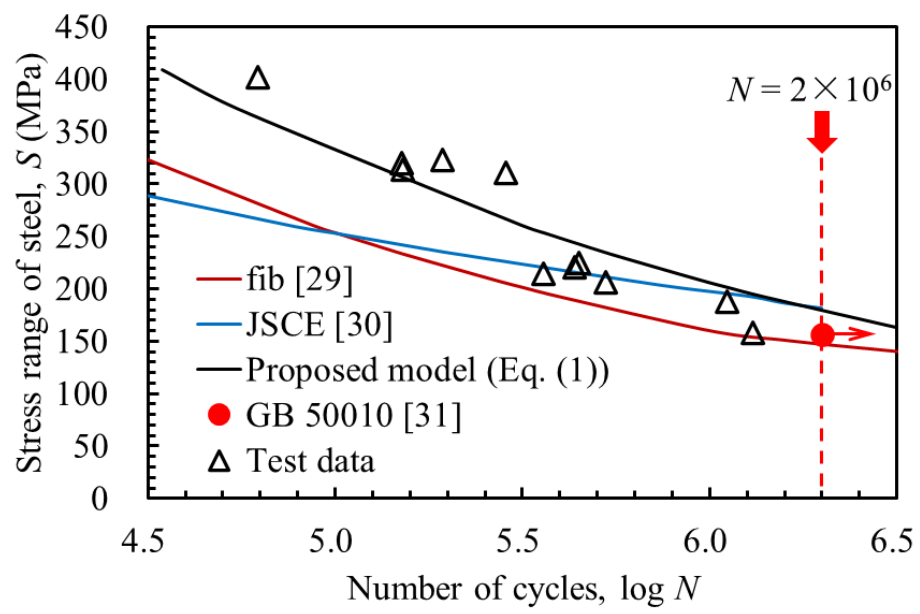

669 Fig. 11. Comparison results of fatigue life of steel in tension between the proposed model and 


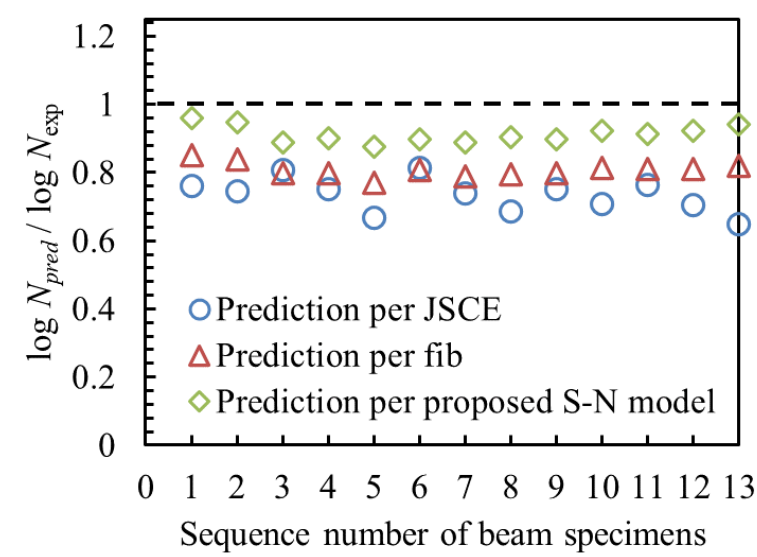

$$
\begin{aligned}
& 1=\text { F0-I0-0.65 } \\
& 2=\text { F0-I20-0.65 } \\
& 3=\text { F2-I0-0.55 } \\
& 4=\text { F2-I0-0.65 } \\
& 5=\text { F2-I0-0.75 } \\
& 6=\text { F2-I } 20-0.55 \\
& 7=\text { F2-I } 20-0.65 \\
& 8=\text { F2-I20-0.75 } \\
& 9=\text { F2-I } 60-0.65 \\
& 10=\text { F2-I } 60-0.75 \\
& 11=\text { F2-I } 100-0.65 \\
& 12=\text { F2-I100-0.75 } \\
& 13=\text { F2-I } 100-0.85
\end{aligned}
$$

(a) Comparison of fatigue life based on the steel stress calculated from the beam theory

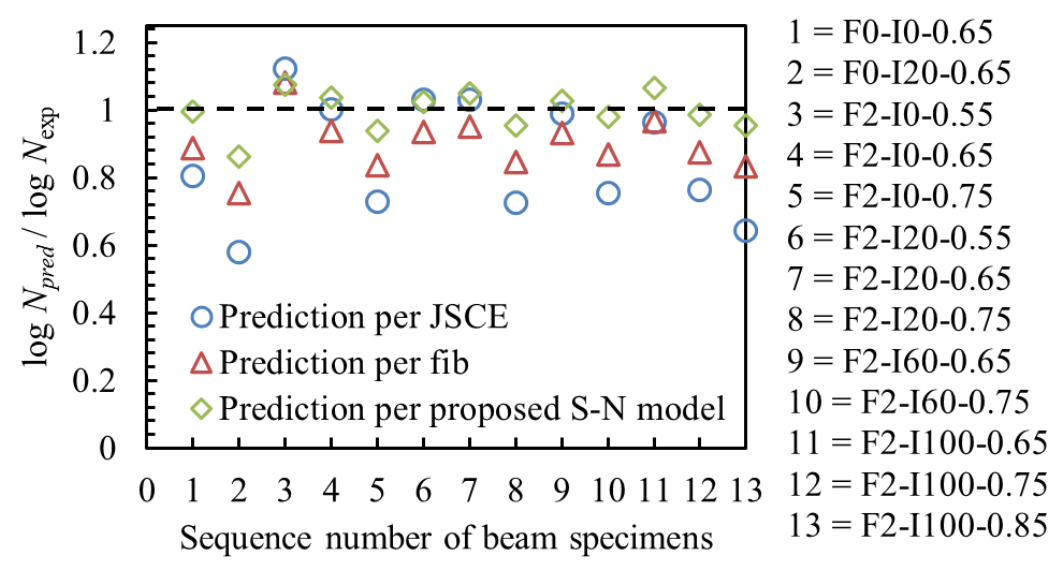

674 (b) Comparison of fatigue life based on the steel stress calculated from the measured strain of steel

reinforcement 
Table 1

678 Labelling of specimens and corrosion degree.

\begin{tabular}{cccc}
\hline Specimens & ICCP, $i\left(\mathrm{~mA} / \mathrm{m}^{2}\right)$ & CF mesh (layers) & Corrosion degree, $\rho(\%)$ \\
\hline F0-I0-S & 0 & 0 & 3.89 \\
F2-I0-S & 0 & 2 & 4.04 \\
F2-I60-S & 60 & 2 & 3.09 \\
F0-I0-0.65 & 0 & 0 & 3.56 \\
F0-I20-0.65 & 20 & 0 & 2.31 \\
F2-I0-0.55 & 0 & 2 & 3.42 \\
F2-I0-0.65 & 0 & 2 & 4.24 \\
F2-I0-0.75 & 0 & 2 & 4.37 \\
F2-I20-0.55 & 20 & 2 & 3.13 \\
F2-I20-0.65 & 20 & 2 & 2.27 \\
F2-I20-0.75 & 20 & 2 & 2.61 \\
F2-I60-0.65 & 60 & 2 & 2.72 \\
F2-I60-0.75 & 60 & 2 & 2.14 \\
F2-I100-0.65 & 100 & 2 & 3.02 \\
F2-I100-0.75 & 100 & 2 & 1.75 \\
F2-I100-0.85 & 100 & 2 & 1.73 \\
\hline
\end{tabular}


681 Mechanical properties of steel in each beam.

\begin{tabular}{|c|c|c|c|c|c|c|c|c|}
\hline \multirow[b]{2}{*}{ Specimens } & \multicolumn{4}{|c|}{ Static performance } & \multicolumn{4}{|c|}{ Fatigue performance } \\
\hline & $f_{y}(\mathrm{MPa})$ & $f_{u}(\mathrm{MPa})$ & $\varepsilon_{y}(\%)$ & $\varepsilon_{u}(\%)$ & $\begin{array}{c}\sigma_{s_{-} \max } \\
(\mathrm{MPa})\end{array}$ & $\begin{array}{c}\sigma_{s_{-} \min } \\
(\mathrm{MPa})\end{array}$ & $\begin{array}{c}S \\
(\mathrm{MPa})\end{array}$ & $\begin{array}{c}N \\
\left(\times 10^{3}\right)\end{array}$ \\
\hline F2-I60-S & 521 & 635 & 2.2 & 7.8 & - & - & - & - \\
\hline F0-I20-0.65 & 506 & 610 & 2.1 & 12.7 & 316 & 63 & 253 & 375 \\
\hline F2-I0-0.55 & 485 & 580 & 2.2 & 8.4 & 261 & 52 & 209 & 706 \\
\hline F2-I0-0.65 & 482 & 584 & 2.2 & 13.5 & 241 & 48 & 193 & 1792 \\
\hline F2-I0-0.75 & 495 & 574 & 2.7 & 5.3 & 251 & 50 & 201 & 702 \\
\hline F2-I20-0.55 & 475 & 575 & 2.3 & 8.6 & 291 & 58 & 233 & 899 \\
\hline F2-I20-0.65 & 490 & 575 & 2.2 & 11.7 & 326 & 65 & 261 & 191 \\
\hline F2-I20-0.75 & 466 & 571 & 2.1 & 13.4 & 462 & 92 & 370 & 79 \\
\hline F2-I60-0.65 & 507 & 611 & 2456 & 12.1 & 296 & 59 & 237 & 545 \\
\hline F2-I60-0.75 & 501 & 606 & 2.6 & 9.2 & 512 & 102 & 410 & 38 \\
\hline F2-I100-0.65 & 501 & 605 & 2.3 & 9.9 & - & - & - & - \\
\hline F2-I100-0.75 & 511 & 593 & 2.2 & 5.2 & - & - & - & - \\
\hline F2-I100-0.85 & 506 & 603 & 2.1 & 7.5 & - & - & - & - \\
\hline
\end{tabular}


684 Failure modes of tested beams.

\begin{tabular}{ccccc}
\hline Specimens & $\begin{array}{c}\text { Number of } \\
\text { fractured } \\
\text { steels }\end{array}$ & $\begin{array}{c}\text { Condition of } \\
\text { concrete in } \\
\text { compressed zone }\end{array}$ & Condition of FRCM & $\begin{array}{c}\text { Location of main } \\
\text { crack }\end{array}$ \\
\hline F0-I0-S & 0 & Crushed & - & Midspan \\
F2-I0-S & 0 & Crushed & Slippage & Midspan \\
F2-I60-S & 0 & Crushed & Slippage & Midspan \\
F0-I0-0.65 & 1 & Crushed & - & Midspan \\
F0-I20-0.65 & 1 & Uncrushed & - & Midspan \\
F2-I0-0.55 & 2 & Uncrushed & Interfacial debonding & Loading point \\
F2-I0-0.65 & 2 & Uncrushed & Slippage \& fracture & Loading point \\
F2-I0-0.75 & 2 & Crushed & Slippage \& fracture & Loading point \\
F2-I20-0.55 & 1 & Uncrushed & Slippage \& fracture & Loading point \\
F2-I20-0.65 & 2 & Uncrushed & Slippage \& fracture & Loading point \\
F2-I20-0.75 & 1 & Crushed & Slippage \& fracture & Midspan \\
F2-I60-0.65 & 1 & Uncrushed & Slippage \& fracture & Midspan \\
F2-I60-0.75 & 2 & Uncrushed & Slippage \& fracture & Midspan \\
F2-I100-0.65 & 1 & Uncrushed & Slippage \& fracture & Midspan \\
F2-I100-0.75 & 1 & Uncrushed & Slippage \& fracture & Loading point \\
F2-I100-0.85 & 2 & Uncrushed & Slippage \& fracture & Midspan \\
\hline
\end{tabular}


Table 4

Key results from fatigue tests.

\begin{tabular}{|c|c|c|c|c|c|c|c|c|c|}
\hline Specimens & $\begin{array}{l}\text { Load ratio } \\
\left(P_{\max } / P_{\mathrm{u} 1}\right)\end{array}$ & $\begin{array}{l}\text { Load ratio } \\
\left(P_{\max } / P_{\mathrm{u} 2}\right)\end{array}$ & $\begin{array}{c}\text { Max. steel stress, } \\
\sigma_{\max }{ }^{1}(\mathrm{MPa})\end{array}$ & $\begin{array}{c}\text { Min. steel stress, } \\
\sigma_{\min }{ }^{1}(\mathrm{MPa})\end{array}$ & $\begin{array}{c}\text { Stress range, } S^{1} \\
(\mathrm{MPa})\end{array}$ & $\begin{array}{l}\text { Max. steel } \\
\text { stress, } \sigma_{\max }^{2} \\
(\mathrm{MPa})\end{array}$ & $\begin{array}{l}\text { Min. steel } \\
\text { stress, } \sigma_{\min }^{2} \\
\quad(\mathrm{MPa})\end{array}$ & $\begin{array}{l}\text { Stress range, } \\
S^{2}(\mathrm{MPa})\end{array}$ & $\begin{array}{l}\text { Experimental } \\
\text { fatigue life } \\
\quad\left(\times 10^{3}\right)\end{array}$ \\
\hline F0-I0-0.65 & 0.65 & 0.63 & 410 & 85 & 325 & 397 & 100 & 297 & 175 \\
\hline F0-I20-0.65 & 0.65 & 0.63 & 410 & 85 & 325 & 502 & 100 & 402 & 206 \\
\hline F2-I0-0.55 & 0.55 & 0.53 & 310 & 42 & 268 & 198 & 40 & 158 & 1300 \\
\hline F2-I0-0.65 & 0.65 & 0.63 & 372 & 54 & 318 & 260 & 39 & 221 & 437 \\
\hline F2-I0-0.75 & 0.75 & 0.73 & 432 & 67 & 365 & 412 & 101 & 311 & 285 \\
\hline F2-I20-0.55 & 0.55 & 0.53 & 310 & 42 & 268 & 227 & 39 & 188 & 1113 \\
\hline F2-I20-0.65 & 0.65 & 0.63 & 372 & 54 & 318 & 246 & 100 & 206 & 528 \\
\hline F2-I20-0.75 & 0.75 & 0.73 & 432 & 67 & 365 & 422 & 99 & 323 & 194 \\
\hline F2-I60-0.65 & 0.65 & 0.63 & 372 & 54 & 318 & 265 & 40 & 225 & 447 \\
\hline F2-I60-0.75 & 0.75 & 0.73 & 432 & 67 & 365 & 421 & 101 & 320 & 151 \\
\hline F2-I100-0.65 & 0.65 & 0.63 & 372 & 54 & 318 & 314 & 40 & 214 & 360 \\
\hline F2-I100-0.75 & 0.75 & 0.73 & 432 & 67 & 365 & 414 & 40 & 314 & 152 \\
\hline F2-I100-0.85 & 0.85 & 0.83 & 494 & 79 & 415 & 502 & 40 & 402 & 62 \\
\hline
\end{tabular}

688 Note: $P_{\mathrm{ul}}$ is the ultimate bearing capacity of reference beam (F0-I0-S); $P_{\mathrm{u} 2}$ is the ultimate bearing capacity of reinforced beam (F2-I0-S); $S$ is the stress range of steel

689 in fatigue loading, $S=\sigma_{\max }-\sigma_{\min } ; \quad{ }^{1}$ Obtained from beam theory; $\quad{ }^{2}$ Obtained from the measured strain of steel reinforcement. 
Table 5

691 Tested and predicted fatigue life of beams (unit: $\times 10^{3}$ cycles).

\begin{tabular}{|c|c|c|c|c|c|c|c|c|}
\hline $\begin{array}{l}\text { Sequence } \\
\text { number }\end{array}$ & Specimens & $\begin{array}{c}\text { Fatigue life } \\
\text { obtained } \\
\text { from tests }\end{array}$ & $\begin{array}{c}\text { Predicted fatigue } \\
\text { life by } \mathrm{JSCE}^{1}\end{array}$ & $\begin{array}{c}\text { Predicted fatigue } \\
\text { life by fib }{ }^{1}\end{array}$ & $\begin{array}{l}\text { Predicted fatigue } \\
\text { life by S-N curve }\end{array}$ & $\begin{array}{c}\text { Predicted fatigue } \\
\text { life by } \mathrm{JSCE}^{2}\end{array}$ & $\begin{array}{c}\text { Predicted fatigue } \\
\text { life by fib }{ }^{2}\end{array}$ & $\begin{array}{l}\text { Predicted fatigue } \\
\text { life by S-N curve }\end{array}$ \\
\hline 1 & F0-I0-0.65 & 175 & 9.7 & 28.9 & 107.0 & 16.4 & 45.5 & 166.9 \\
\hline 2 & F0-I20-0.65 & 206 & 9.2 & 28.9 & 107.0 & 1.2 & 10.0 & 37.9 \\
\hline 3 & F2-I0-0.55 & 1300 & 85.2 & 75.3 & 273.2 & 7301.9 & 4050.0 & 3681.9 \\
\hline 4 & F2-I0-0.65 & 437 & 17.2 & 32.2 & 119.1 & 446.2 & 199.8 & 710.6 \\
\hline 5 & F2-I0-0.75 & 285 & 4.3 & 16.1 & 60.3 & 9.4 & 36.0 & 132.8 \\
\hline 6 & F2-I20-0.55 & 1113 & 84.7 & 75.3 & 273.2 & 1718.1 & 451.3 & 1578.2 \\
\hline 7 & F2-I20-0.65 & 528 & 16.9 & 32.2 & 119.1 & 787.8 & 282.7 & 998.1 \\
\hline 8 & F2-I20-0.75 & 194 & 4.3 & 16.1 & 60.3 & 6.8 & 29.9 & 110.6 \\
\hline 9 & F2-I60-0.65 & 447 & 17.8 & 32.2 & 119.1 & 391.8 & 181.8 & 648.0 \\
\hline 10 & F2-I60-0.75 & 151 & 4.6 & 16.1 & 60.3 & 8.2 & 31.4 & 116.2 \\
\hline 11 & F2-I100-0.65 & 360 & 17.7 & 32.2 & 119.1 & 230.3 & 232.5 & 824.4 \\
\hline 12 & F2-I100-0.75 & 152 & 4.5 & 16.1 & 60.3 & 9.1 & 34.2 & 126.3 \\
\hline 13 & F2-I100-0.85 & 62 & 1.3 & 8.5 & 32.2 & 1.2 & 10.0 & 37.9 \\
\hline
\end{tabular}

Note: ${ }^{1}$ Calculated based on the beam theory; ${ }^{2}$ Calculated based on the measured strain of steel reinforcement. 
Table 6 Available test data in literature.

\begin{tabular}{|c|c|c|c|c|c|c|}
\hline Sources & $\begin{array}{c}\text { Corrosion } \\
\text { of steel }(\%) \\
\end{array}$ & Strengthening & Load level, $S_{L}$ & $\begin{array}{c}\text { Maximum steel } \\
\text { stress, } \sigma_{\max }(\mathrm{MPa}) \\
\end{array}$ & $\begin{array}{l}\text { Stress range of steels in } \\
\text { tension, } S(\mathrm{MPa}) \\
\end{array}$ & $\begin{array}{l}\text { Experimental cycles to } \\
\text { failure, } N\left(\times 10^{3} \text { cycles }\right)\end{array}$ \\
\hline \multirow{3}{*}{ Barnes et al. [23] } & 0 & \multirow{3}{*}{ CFRP plates } & 0.39 & 303 & 272 & 508 \\
\hline & 0 & & 0.32 & 247 & 222 & 1889 \\
\hline & 0 & & 0.26 & 198 & 180 & $>2000$ \\
\hline \multirow{4}{*}{ Song et al. [37] } & 8.3 & \multirow{4}{*}{ CFRP sheets } & 0.39 & - & - & 1346 \\
\hline & 13.8 & & 0.39 & - & - & 459 \\
\hline & 15.0 & & 0.39 & - & - & 610 \\
\hline & 16.7 & & 0.39 & - & - & 304 \\
\hline \multirow{8}{*}{ Papakonstantinou et al. [40] } & 0 & \multirow{8}{*}{ GFRP sheets } & 0.36 & 231 & 212 & $>2000$ \\
\hline & 0 & & 0.41 & 258 & 239 & 685 \\
\hline & 0 & & 0.43 & 256 & 244 & 880 \\
\hline & 0 & & 0.45 & 268 & 250 & 800 \\
\hline & 0 & & 0.49 & 287 & 269 & 570 \\
\hline & 0 & & 0.53 & 331 & 312 & 235 \\
\hline & 0 & & 0.59 & 378 & 349 & 126 \\
\hline & 0 & & 0.73 & 427 & 402 & 31 \\
\hline \multirow{6}{*}{ Masoud et al. [41] } & 5.5 & \multirow{6}{*}{ CFRP sheets } & - & 378 & 336 & 118 \\
\hline & 9.0 & & - & 389 & 346 & 95 \\
\hline & 10.5 & & - & 392 & 348 & 101 \\
\hline & 5.5 & & - & 316 & 281 & 232 \\
\hline & 9.0 & & - & 321 & 285 & 209 \\
\hline & 10.5 & & - & 322 & 286 & 216 \\
\hline
\end{tabular}


Table 6 Cont.

\begin{tabular}{|c|c|c|c|c|c|c|}
\hline Sources & $\begin{array}{c}\text { Corrosion } \\
\text { of steel }(\%) \\
\end{array}$ & Strengthening & Load level, $S_{L}$ & $\begin{array}{c}\text { Maximum steel } \\
\text { stress, } \sigma_{\max }(\mathrm{MPa}) \\
\end{array}$ & $\begin{array}{l}\text { Stress range of steels in } \\
\text { tension, } S(\mathrm{MPa})\end{array}$ & $\begin{array}{l}\text { Experimental cycles to } \\
\text { failure, } N\left(\times 10^{3} \text { cycles }\right)\end{array}$ \\
\hline \multirow{5}{*}{ Charalambidi et al. [42] } & 0 & \multirow{5}{*}{ CFRP plates } & 0.77 & 402 & 352 & 990 \\
\hline & 0 & & 0.78 & 414 & 365 & 1450 \\
\hline & 0 & & 0.73 & 403 & 352 & 807 \\
\hline & 0 & & 0.74 & 416 & 373 & 696 \\
\hline & 0 & & 0.70 & 396 & 340 & 774 \\
\hline \multirow{4}{*}{ Aidoo et al. [43] } & 0 & \multirow{4}{*}{ CFRP plates } & 0.65 & 380 & 338 & 309 \\
\hline & 0 & & 0.51 & 279 & 279 & 1280 \\
\hline & 0 & & 0.65 & 380 & 306 & 193 \\
\hline & 0 & & 0.51 & 279 & 279 & 960 \\
\hline
\end{tabular}


Table 7

698 Limit stress range of steel reinforcement.

\begin{tabular}{ccc}
\hline $\begin{array}{c}\text { Steel stress ratio } \\
\left(\sigma_{\min } / \sigma_{\max }\right)\end{array}$ & \multicolumn{2}{c}{ Limit steel stress range $\left(\sigma_{\max }-\sigma_{\min }\right),(\mathrm{MPa})$} \\
\cline { 2 - 3 } 0 & HRB 335 & HRB 400 \\
\hline 0.1 & 175 & 175 \\
0.2 & 162 & 162 \\
0.3 & 154 & 156 \\
0.4 & 144 & 149 \\
0.5 & 131 & 137 \\
0.6 & 115 & 123 \\
0.7 & 97 & 106 \\
0.8 & 77 & 85 \\
0.9 & 54 & 60 \\
\hline
\end{tabular}

699 
Table 8

701 Comparison of predicted fatigue life on HRB 335 and HRB 400 steels rebars.

\begin{tabular}{lccc}
\hline & Descriptions of items & \multicolumn{2}{c}{ Type of steel rebars } \\
\cline { 2 - 4 } & Nominal yielding strength, $f_{s y}(\mathrm{MPa})$ & 335 & 400 \\
& Nominal ultimate strength, $f_{\text {su }}(\mathrm{MPa})$ & 455 & 540 \\
& Diameter, $\phi(\mathrm{mm})$ & 12 & 12 \\
& HRB 400 \\
\hline \multirow{3}{*}{ Information of steel } & Steel stress ratio, $\sigma_{\min } / \sigma_{\max }(\mathrm{MPa})$ & 0.2 & 0.2 \\
& Stress range, $\sigma_{\max }-\sigma_{\min }(\mathrm{MPa})$ & 154 & 156 \\
& Minimum stress, $\sigma_{\min }(\mathrm{MPa})$ & 38.5 & 39 \\
& Maximum stress, $\sigma_{\max }(\mathrm{MPa})$ & 192.5 & 195 \\
\hline \multirow{2}{*}{ Prediction of fatigue } & fib model code $[29]$ & 10.1 & 7.1 \\
life, $N\left(\times 10^{6}\right.$ cycles $)$ & JSCE [30] & 7.7 & 7.8 \\
& GB 50010 [31] & 2.0 & 2.0 \\
\hline
\end{tabular}

